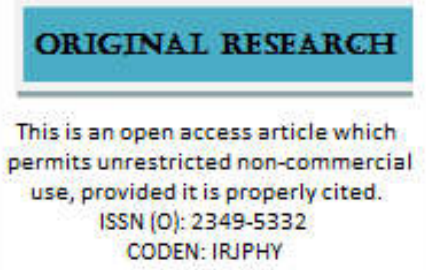

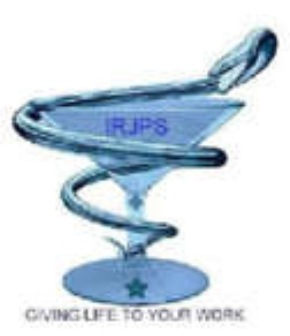

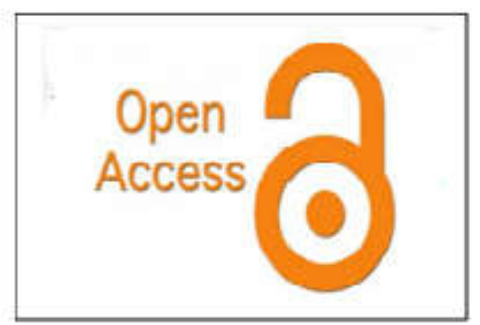

\title{
A NOVEL POTENTIAL PLANT: CREPIDIUM VERSICOLOR AGAINST WOUND MICROBES
}

\author{
S. S. Rahangdale ${ }^{1 *}$, S. R. Rahangdale ${ }^{2}$, A. N. Khupat ${ }^{1}$
}

${ }^{1}$ Dept. of Botany, Hon. B.J. Arts, Commerce \& Science College, Ale, Dist.: Pune, Maharashtra, India.

${ }^{2}$ Dept. of Botany, A.W. Arts, Science \& Commerce College, Otur, Dist.: Pune, Maharashtra, India.

Submitted on: 03.05.19;

\section{Accepted on: 22.05.19}

\begin{abstract}
Wound microbes are making complications in the wound healing process. An array of wound microbes is effectively inhibited with crude aqueous methanolic extract of Crepidium versicolor (Lindl.). pseudo-stems. Results of the study revealed that, the plant extract is highly efficient in controlling the wound microbes, viz., Escherchia coli, Staphylococcus aureus and Methicillin-resistant Staphylococcus aureus, than that of the most popular antibiotics being used. The plant is thus found to have novel properties which are being reported for the first time. This may be a potential candidate for the antibiotic herbal source against wound microbes.
\end{abstract}

KEY WORDS: Crepidium versicolor (Lindl.), Plant extract, Agar cup diffusion method, Antibacterial activity

Corresponding author: S. S. Rahangdale E-mail: rsanjay2@hotmail.com
Indian Research Journal of Pharmacy and Science; 21(2019)1839-1844; Journal Home Page: https://www.irjps.in DOI: 10.21276/irjps.2019.6.2.2 


\section{INTRODUCTION}

According to World Health Organization (WHO) more than $80 \%$ of the world's population relies on traditional medicines for their primary healthcare needs (Ahmadullah and Nayar, 1999). Use of herbal medicines in Asia represents a long history of human interactions with the environment. Plants used for traditional medicine contain a wide range of substances that can be used to treat chronic as well as infectious diseases. A vast knowledge of how to use the plants against different illnesses may be expected to have accumulated in areas where the use of plants is still of great importance. The medicinal value of plants lies in some chemical substances that produce a definite physiological action on the human body. Important bioactive compounds of plants which are responsible for wound healing are alkaloids, flavanoids, tannins, phenolic compounds, essential oils, sesquiterpenes, saponins, allantoins, benzoylesters, alkylamides, polysaccharides and fatty oils. Therefore, the plants are being always used by the native peoples as medicines while, the scientific community is in search of novel compounds and applications of plants to be used as medicines or sources of base molecules. These molecules are either used directly or sometimes their derivatives with more potentiality (Ncube, 2008) are used.

Due to continuous usage of same type of antibiotic drugs, the human pathogens develop resistance against the drugs. This has created a necessity to search for new antimicrobial substances from other sources including plants. Screening of medicinal plants for antimicrobial activities and phytochemicals is important for finding potential new compounds for therapeutic use.

In this respect, during documentation of ethno-botanical information and folk medicines of tribal peoples in Pune district, present plant was found to be used against the dysentery and stomach problems during rainy season. The stomach problems in the hilly areas are basically due to contamination of water sources and the symptoms are dysentery and stomachache. In absence of immediate medical facilities, these problems are being solved by local peoples by taking a small piece of fresh pseudo-stem along with little jaggery. The jaggery is being used to nullify the bitter taste of the crude drug. It is also being used to cure certain skin infections, like skin rashes. The identity of the crude drug plant was then confirmed with the help of available literature as, Crepidium versicolor (Lindl.) Sushil K. Singh et.al. belonging to the family Orchidaceae (Santapau H. and Z. Kapadia, 1966; Sharma B. D., S. Karthikeyan and N. P. Singh (eds.) 1996, Jalal J.S., 2018). This species is commonly found in Maharashtra and other states of India but the population is scattered and very small at many places.

A review of literature revealed that the herbal medicine used in the traditional medicine provide interesting information regarding unexplored source for development of new drug. 'Charaka Samhita' is one of the oldest literature in which Indian orchids and their uses are reported. It is the first Indian orchid record regarding use of orchids in Ayurvedic medicine (Manilal and Sathish Kumar, 1986). The leaf extract of plant is purgative and is used in treating infantile epilepsy (Dalgado, 1896). Crepidium versicolor contains important secondary metabolites Malaxin. (Luning, 1967; Lawler and Staytor, 1969).

All these references related to leaf as a part of crud drug. Very trace references related to pseudo-bulb. Therefore, the plant was selected for basic analysis regarding the antimicrobial activity against wound microbes on the basis of its usage by local peoples as the phytochemical research based on ethno-pharmacological information is generally considered an effective approach in the discovery of new anti-infective agents from higher plants.

\section{WOUND MICROBIOLOGY}

Wounds are broadly classified into primary, secondary and tertiary wounds. Primary wound includes cuts, stabs, abrasions, scratches etc; the secondary wound includes bites, fissures, burns, contusions etc; while the tertiary wound are deep cut wounds. Secondary and tertiary wounds are slower to heal since new tissue (granulation tissue) has to be formed and the process is often accompanied by infections. All wounds may be contaminated with microbes, but in most cases the infection does not develop due to innate host defense which eliminates contaminants. A complex interplay between host, microbial and surgical factors ultimately determines the prevention or establishment of a wound infection. Once the infection is established the wound healing is delayed and also sometimes creates further complications. 
For an ideal wound healing a drug or a plant should have the properties,i) haemostyptic (able to stop bleeding), ii) disinfectant (preventing infections), iii) wound cleaning (able to remove any foreign matter adhered to the wound), iv) analgesic and anti-inflammatory (to relieve local pain and inflammation), and $\mathrm{v}$ ) astringent (able to precipitate the skin proteins for better scab formation and for contracting body tissue especially to check bleeding). Among the main factors affecting wound healing are the primary and secondary infections if any (array of microbes present on the wounds), host defense mechanisms and capacity and the environmental factors.

Common pathogens associated with wound infections are Staphylococcusaureus, Coagulasenegative Staphylococci, Enterococci, Escherichia coli, Pseudomonas aeruginosa, Enterobacter sp., Proteus mirabilis andKlebsiella pneumonia.

\section{MATERIALS}

\section{a) Plant material and preparation of extract}

Fresh plant material used in this study consisted of Crepidium versicolor (Lindl.) Sushil K. Singh et.al. obtained from different parts of Northern Maharashtra state studied by authors.

\section{b) Test Microorganisms}

Escherchia coli, Staphylococcus aureus and Methicillin - resistant Staphylococcus aureus these three bacterial strains were used as test microorganisms.

\section{METHODS}

\section{Preparation of plant extracts}

The material was chopped and dried under shade. All the solvents used were of AR grade. Air dried pseudo-stemswere extracted with different solvents like chloroform, dichloromethane, diethyl ether, ethyl acetate, ethanol, methanol, n-hexane and distilled water.

The plant material was homogenized in various solvents with varying polarities.

Accurately weighed, 1 gram dried plant powder was taken in 8 dry, sterile, clean, stopper test tubes (capacity $20 \mathrm{~cm}^{3}$ ). Ten $\mathrm{cm}^{3}$ of $\mathrm{n}$-hexane, diethylether, dichloromethane, chloroform, ethyl acetate, methanol, ethanol and distilled water were added separately to each test tubes containing plant powder.Test tubes were kept for extraction on a rotary shaker at $35 \mathrm{rpm}$ and at room temperature $\left(28^{\circ} \mathrm{C} \pm 2^{\circ} \mathrm{C}\right)$ for 12 hours. The contents of the test tubes were then filtered through whatman filter paper no. 41.The filtrates were collected in dry, clean beakers and were evaporated to dryness on a water bath at a temperature of $80^{\circ} \mathrm{C}$. The residue was reconstituted in $0.5 \mathrm{~cm}^{3}$ of DMSO.

\section{ANTIBACTARIAL TESTING}

\section{Preparation of agar cups}

Cups in each plate having the diameter of $8 \mathrm{~mm}$ were punctured in agar using flame sterilized cork borer. Using a micropipette with a sterile pipette tip, $50 \mu 1$ of positive control, negative control and plant extracts were added. Since the extracts were dissolved in Dimethyl sulphoxide (DMSO), it was used as negative control to confirm that the zone of inhibition was due to the antimicrobial components present in the plant extracts and not because of the DMSO. The petri-plates were kept for incubation at $37^{\circ} \mathrm{C}$, for 18 hours. After incubation, the plates were inspected to identify zones of inhibition of different extracts. The diameter of each zone of inhibition was measured.

\section{Preparation of Standards \\ - Positive control}

Using serial dilution technique $10 \mathrm{ppm}$ standard solutions were prepared. Ciprofloxacin was used as standard for the bacterial strains viz., $S$. aureus, $E$. coli. Vancomycin was used as standard for the MRSA.

\section{- Negative control}

Dimethyl sulphoxide (DMSO) was used as negative control as all the plant extracts were finally reconstituted in DMSO as it enhances the penetration of extracts through agar without itself showing any antimicrobial activity.

\section{Preparation of Inoculum}

Inoculum was prepared using $18 \mathrm{hrs}$ old broth cultures of all the organisms used and were incubated at $37^{\circ} \mathrm{C}$. Optical density of broth was adjusted to 0.1 using $\mathrm{MH}$ broth for all the bacterial strains. 
RESULT

Table 1: Screening of plant extract with different grade of solvents against pathogen.

\begin{tabular}{|c|c|c|c|c|c|c|c|c|}
\hline \multirow{2}{*}{ Pathogen } & \multicolumn{7}{|c|}{ Zone of inhibition (mm) } \\
\cline { 2 - 9 } & $\begin{array}{c}\text { n- } \\
\text { Hexane }\end{array}$ & $\begin{array}{c}\text { Diethyl } \\
\text { ether }\end{array}$ & $\begin{array}{c}\text { Dichloro } \\
\text { methane }\end{array}$ & $\begin{array}{c}\text { Chloro } \\
\text { form }\end{array}$ & $\begin{array}{c}\text { Ethyl } \\
\text { acetate }\end{array}$ & Methanol & Ethanol & Distilled water \\
\hline SA & - & 11 & 14 & 13 & 14 & 11 & - & 12 \\
\hline MRSA & - & - & 11 & 13 & 13 & 19 & 15 & 12 \\
\hline EC & - & - & - & - & - & - & 09 & - \\
\hline
\end{tabular}

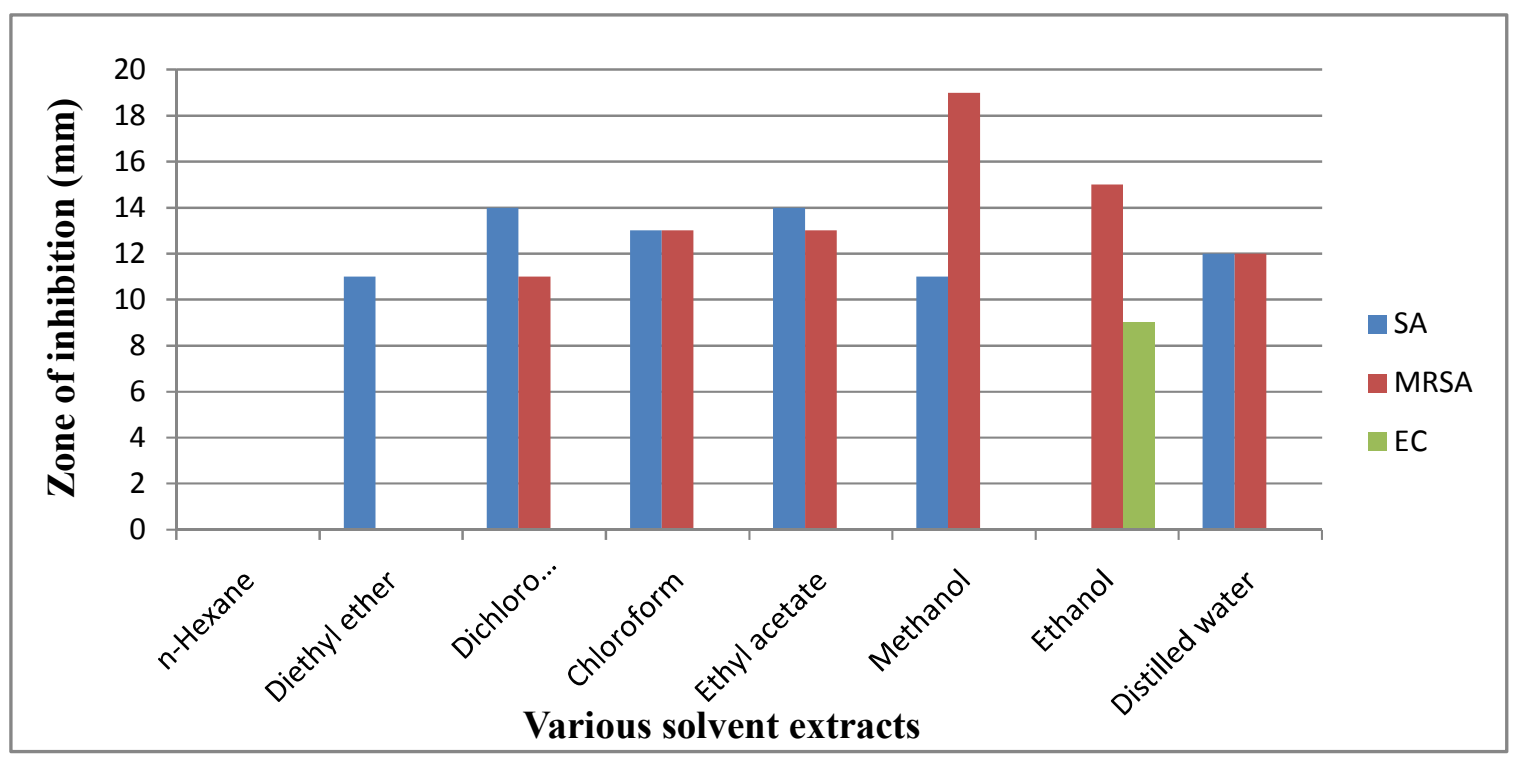

Figure 1: Antibacterial activity of plant extract of Crepidium versicolor against pathogenic bacteria.

Table 2: Screening of plant extract with antibiotic against $50 \%$ methanol and $50 \%$ water (Hydromethanolic extract).

\begin{tabular}{|c|c|c|}
\hline \multirow{2}{*}{ Organisms } & \multicolumn{2}{|c|}{ Zone of inhibition in mm } \\
\cline { 2 - 3 } & Vancomycin/Ciprofloxacin & $\begin{array}{c}\text { Hydromethanolic extract } \\
\text { (Methanol : Water 50:50 v/v) }\end{array}$ \\
\hline SA & 21 & 13 \\
\hline MRSA & 20 & 36 \\
\hline EC & 40 & 14 \\
\hline
\end{tabular}




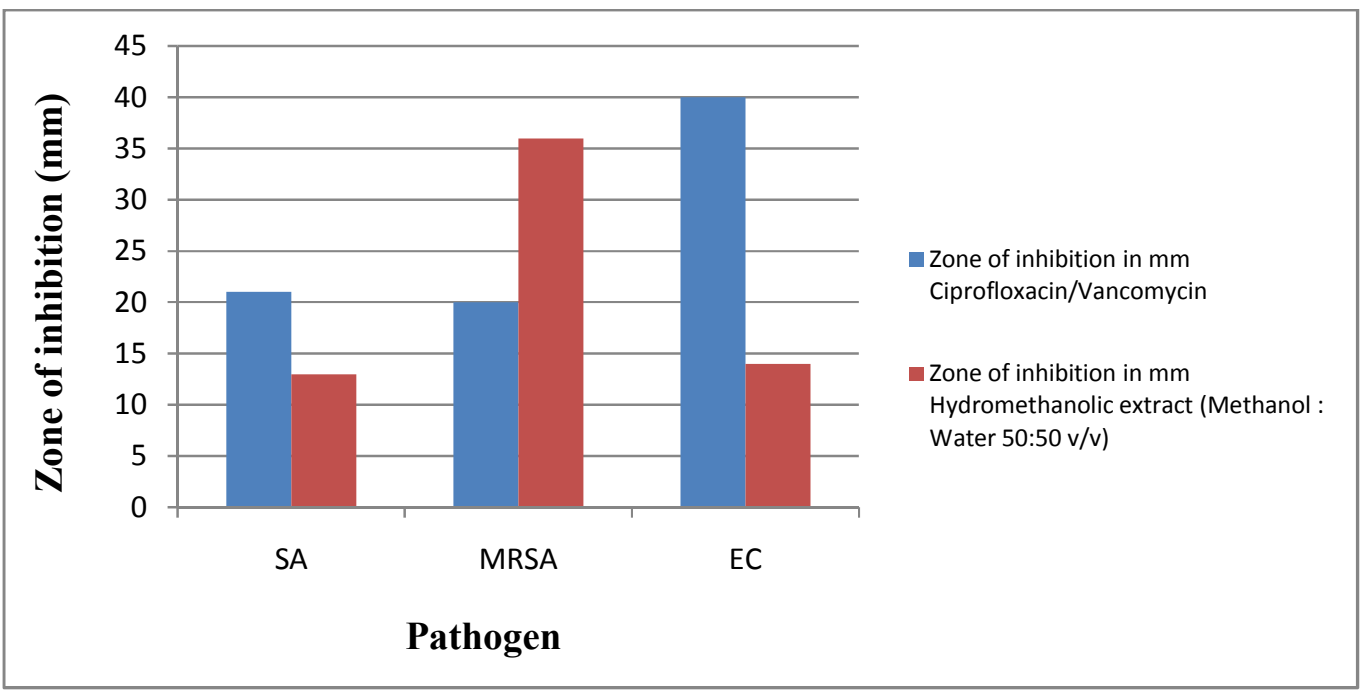

Figure-2 Susceptibility pattern of tested wound microbes against hydromethanolic plant extract and control antibiotics.
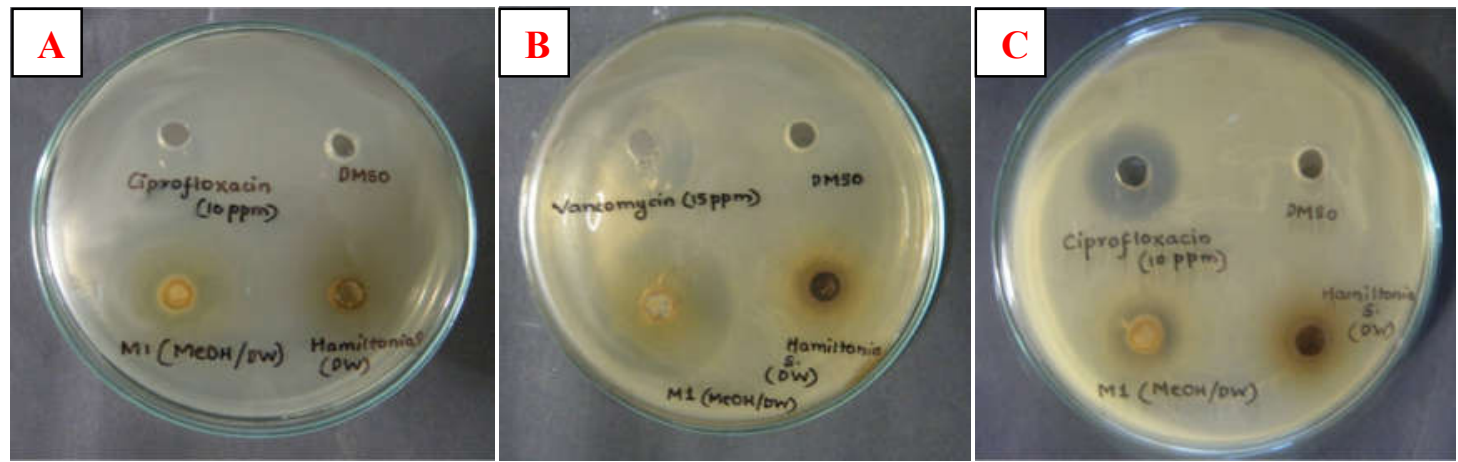

Figure-3 Plate showing comparative antibacterial activity of hydromethanolic plant extract(M1) of Crepidium versicolor against different pathogens (Bacterial strains A-S. aureus, B-Methicillin resistant S. aureus, C- E. coli).

\section{RESULT AND DISCUSSION}

The plant extract was treated with different grade of solvents. The zone of inhibition of each solvent varies considerably against gram positive $(S$. aureus) and gram negative (E. coli) bacteria also with Methicillin resistant Staphylococcus aureus (MRSA).The observed zone of inhibition ranging from $09 \mathrm{~mm}$ to $19 \mathrm{~mm}$. The highest zone of inhibition of $S$. aureus (SA) was observed similar in dichloromethane and ethyl acetate (14mm) whereas the lowest zone of inhibition was seen in diethyl ether and methanol $(11 \mathrm{~mm})$. In case of Methicillin resistant $S$. aureus (MRSA) the highest (19mm) and the lowest $(11 \mathrm{~mm})$ zone of inhibition were recorded in methanol and dichloromethane respectively. In $E$. coli (EC) the zone of inhibition was recorded only in ethanol $(09 \mathrm{~mm})$ while the rest of the solvents did not show any activity.

It showed that the zone of inhibition was significantly enhanced in the solvent methanol and subsequently decreased in the order ethyl acetate, dichloro methane, chloroform, distilled water, diethyl ether and ethanol. The plant extract in nhexane did not show the activity against all the tested bacteria. The highest zone of inhibition was found in MRSA (19mm) with methanolic plant 
extract whereas the lowest zone of inhibition was seen in E. coli $(09 \mathrm{~mm})$ with ethanolic plant extract (Table-1 and Figure-1).

The antibacterial activity of MRSA in hydromethanolic plant extract $(36 \mathrm{~mm})$ was recorded more compared with commercial antibiotic vancomycin (20mm) while in case of $S$. aureus and E. coli reversed zone of inhibition were recorded which showed the minimum activity in hydromethanolic plant extract $(13 \mathrm{~mm}$ and $14 \mathrm{~mm})$ and the maximum activity was found in the antibiotic ciprofloxacin $(21 \mathrm{~mm}$ and $40 \mathrm{~mm})$ respectively (Table-2 and Figure-2\&3).

\section{CONCLUSION}

The hydro-methanolic medium is more potent as compared to the solvents for this plant. The plant

\section{REFERENCES}

1. Ahmedullah M. andNayar M.P. Red data book of Indian plants (PensularIndia), Culcutta: Botanical survey of India. 1999. Vol.4.

2. Dalgado, Vires plantarummalabaricum. Rangel Quinta de Boa Vista. Bastora.Goa. 1896.

3. Luning Studies on Orchidaceae alkaloids IV Screening of species for alkaloids photochemistry 1967. 6: 857-861.

4. Lawler and Staytor, The distribution of alkaloids in orchids from the Territory of Papus New Guinea Proc.Linn.Soc.NSW 1969. 94:419-421.

5. Manilal and Sathish Kumar, Research on Indian Orchids in Biology conservation and Culture of orchids Vij. S.P. 1986. (ed)1-2. studied has inhabiting activity against SA, MRSA and $\mathrm{EC}$, but as compared to common commercial antibiotics it has less activity against SA and EC. For MRSA it has significantly more activity compared with antibiotics. This study revealed that it is an important and a key potential drug plant against MRSA.

\section{ACKNOWLEDEMENT}

Authors are grateful to the Principals and Authorities of Hon. B. J. College, Ale and Principal, A.W. College, Otur for providing necessary laboratory facilities. The support and help rendered from Shawara Husen and Authorities of Department of Microbiology, G. N. Khalsa College, Matunga, Mumbai: 400019 for microbial primary analysis.

6. N.Cube NS, Afolayas AJ and Okoh A. Assessment techniques of antimicrobial properties of natural compounds of plant origin current methods and future trends. African Journal of Biotechnology, 2008. 7(12), $1797-$ 1806.

7. Santapau H. and Z. Kapadia The Orchids of Bombay. Manager of Publication, Delhi. 1966.

8. Sharma B. D., S. Karthikeyan and N. P. Singh (eds.) Flora of Maharashtra State, Monocotyledons. Botanical Survey of India, Calcatta. 1996

9. Jalal J.S. Orchids of MaharashtraBotanical Survey of India, Kolkata, 2018; 57-58. 